\title{
Evaluation on Shear Bond Strength of Different Glass Ionomer and Hydroxy Apatite Cements Used in Ossiculoplasty
}

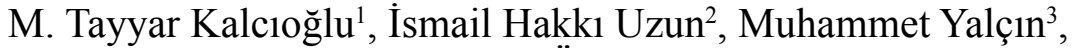 \\ Meral Arslan Malkoç², Ayşe Tuba Öğreten², Fatih Mehmet Hanege ${ }^{4}$ \\ ${ }^{1}$ Department of Otorhinolaryngology, İstanbul Medeniyet University Faculty of Medicine, Göztepe Training and Research Hospital, İstanbul, Turkey \\ ${ }^{2}$ Department of Prosthodontics, İnönü University Faculty of Dentistry, Malatya, Turkey \\ ${ }^{3}$ Department of Restorative Dentistry, İnönü University Faculty of Dentistry, Malatya, Turkey \\ ${ }^{4}$ Department of Otorhinolaryngology, İstanbul Medeniyet University, Goztepe Training and Research Hospital, İstanbul, Turkey
}

Background: Glass ionomer cements (GIC) have been widely used in dentistry for many years. In recent years, GIC have also been used for ossiculoplasty. The bond strength of GIC used in ossiculoplasty and the way they may change over the years in the cementation area are being questioned. The bonding strength of the substance may be of importance for long-term outcomes.

Aims: The aim of this study was to investigate the bond strength of different GIC on ossicles.

Study Design: In vitro study.

Methods: Twenty ossicles were obtained from patients who had undergone ear surgery. All specimens were randomly divided into four subgroups. All specimens were inserted into a specially designed apparatus for shear bond strength (SBS) testing. The tested materials [Aqua Meron (AM), Aqua Cem (AC), Ketac Cem $(\mathrm{KC})$, and Otomimix $\mathrm{CPB}(\mathrm{OH})]$ were prepared and applied according to the manufacturer's instructions. The SBS was tested using a universal testing machine at a crosshead speed of $0.5 \mathrm{~mm} / \mathrm{min}$.

Results: The mean SBSs were found to be $13.28 \mathrm{MPa}$, 23.43 $\mathrm{MPa}, 8.51 \mathrm{MPa}$, and $1.78 \mathrm{MPa}$ for $\mathrm{AM}, \mathrm{AC}, \mathrm{KC}$, and $\mathrm{OH}$, respectively. AC had the highest SBS, which was statistically significantly different from that of $\mathrm{KC}$ and $\mathrm{OH}(\mathrm{p}<0.05)$. Both $\mathrm{AM}$ and $\mathrm{KC}$ had higher SBS than $\mathrm{OH}(\mathrm{p}<0.05)$.

Conclusion: The results obtained in this study by investigating the bone-bonding strength of cements widely used in ossiculoplasty demonstrate that some of these substances have a greater ability to bond to ossicles compared to others. Further clinical investigations are needed to test different parameters.

Keywords: Bone cement, bond strength, ossicles, ossiculoplasty
The natural ossicular chain plays an important role in transporting sound efficiently from the environment to the oval window (1). Diseases of the middle ear, such as chronic otitis media, cholesteatoma, and trauma, can interrupt this transfer.
Incudostapedial joint discontinuity is the most common ossicular defect encountered in tympanoplasty $(2,3)$. Other problems of the ossicular chain include a defective stapes superstructure with or without a defective incus, and defective malleus (4).

This study was presented at the $2^{\text {nd }}$ Meeting of European Academy of ORL-HNS, 27-30 April, 2013, Nice, France and $1^{\text {st }}$ Global Otology Research Meeting within the 29th Politzer Society Meeting, 13-17 November, 2013, Antalya, Turkey.

Address for Correspondence: Dr. M. Tayyar Kalcıoğlu, Department of Otorhinolaryngology, İstanbul Medeniyet University Faculty of Medicine, Göztepe Training and Research Hospital, İstanbul, Turkey

Phone: +90 5324330695 e-mail: mtkalcioglu@hotmail.com

Received: 24.09.2014 Accepted: 30.10.2014 • DOI: 10.5152/balkanmedj.2015.15829

Available at www.balkanmedicaljournal.org 


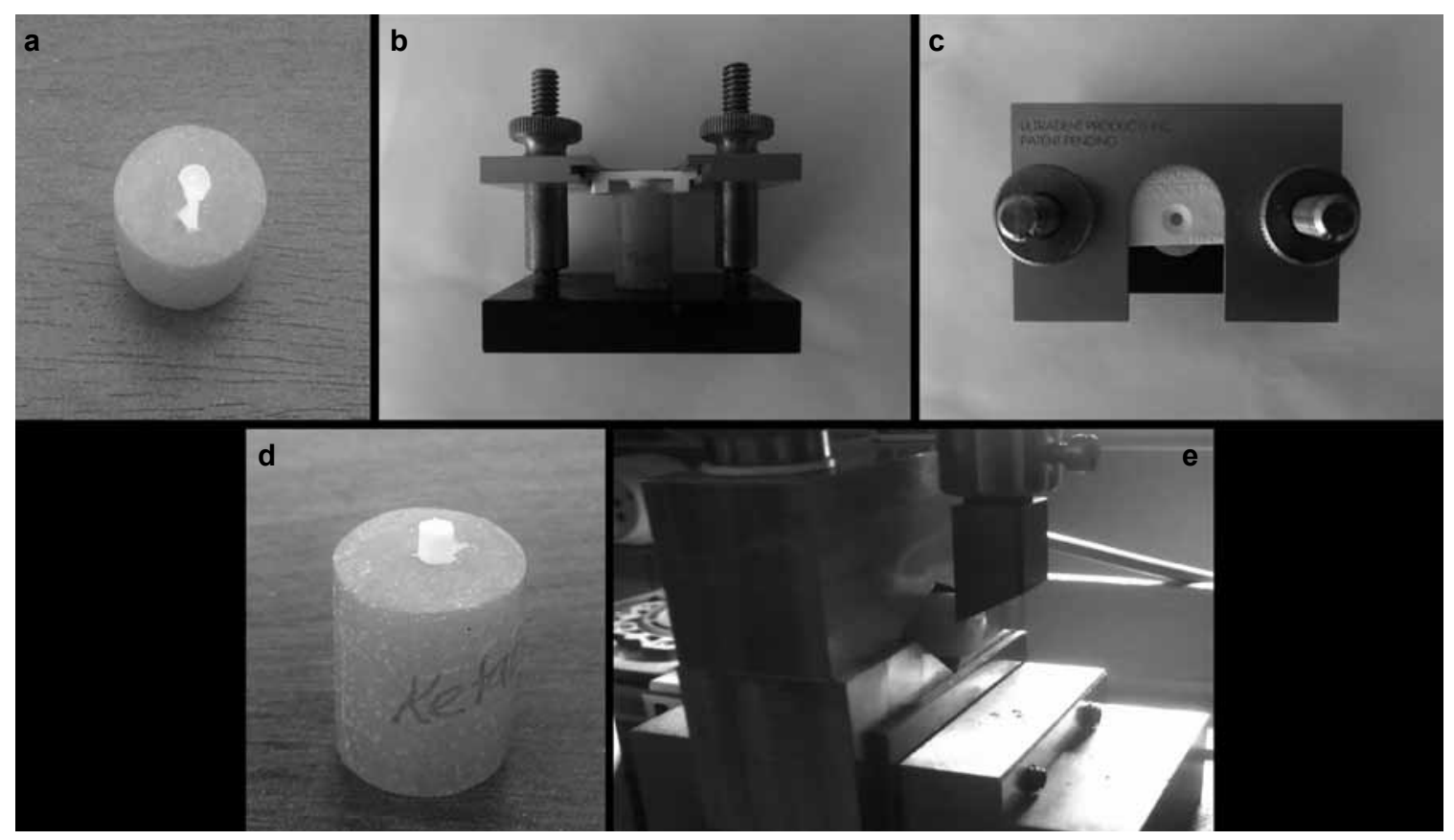

FIG. 1. a-e. Preparation of test specimen and SBS testing. Ossicles embedded into the auto-polymerised acrylic resin (a). Specimen placed onto the special apparatus designed for SBS (b), specimen placed onto the special apparatus designed for SBS (c), specimen ready for SBS testing (d), SBS testing with universal testing machine (e)

Ossicular chain reconstructions with total and partial ossicular replacement prostheses and incus repositions are the most frequently used treatment options for these problems (5-7). Most of these treatment options have aimed to transport the sound into the oval window via a prosthesis. Successful ossicular reconstruction requires a stable connection between the vibrating tympanic membrane and the inner ear. Although replacement with a prosthesis is extensively used, this prosthesis can dislocate over time, resulting in decreasing long-term hearing quality. It was reported that, in patients requiring revision of ossiculoplasty, half of the failures result from displacement of the prosthesis (4). While the incus reposition is simple and cost effective, the prosthetic rehabilitations are time consuming and highly costing.

Glass ionomer cements (GIC) have been widely used in dentistry for many years. Among the different treatment options, GICs have also been used for ossiculoplasty for two decades. Geyer and Helms first reported its use in middle ear surgery, in the 1990s (8). It is now used in ear surgery for various indications, such as ossicular reconstruction, bony external ear canal repair, stabilisation of cochlear implants, repair of dural defects, and reconnecting of gaps created by incudostapedial necrosis (9). Several studies have shown that there was a considerable increase in patients' hearing quality when ossicular chain was rebuilt with GIC $(4,10-14)$. The ideal bone cement used for this purpose should be malleable, easily applied, rapidly setting, non-toxic, fluid resistant, capable of osteointegration, and able to incite minimal inflammation (1).
There are different types of GICs which have different powders used for ossiculoplasty in the literature. The bond strength of GICs used in ossiculoplasty and the way in which they may change over the years in the cementation area are being questioned. The bonding strength of the substance may be of importance for the long-term outcomes. The aim of this in vitro study was to evaluate the shear bonding strength of three different GIC used in literature and Hydroxyapatite (HA) for ossicular chain reconstruction materials.

\section{MATERIALS AND METHODS}

In this study, we used twenty ossicles removed from the patients, who were operated upon due to advanced ear disease, after local ethic committee approval (2012/61) and after obtaining written informed consent from all subjects.

\section{Specimen preparation}

In total, twenty ossicles were prepared and kept in alcohol solutions until the shear bond strength testing (SBS) was performed. Aqua Meron (AM), Aqua Cem (AC), Ketac Cem $(\mathrm{KC})$, and Otomimix $\mathrm{CPB}(\mathrm{OH})$, which are frequently used bone cements for ossiculoplasty, were used as testing materials in the current study (Table 1). Bone specimens were embedded into the auto-polymerised acrylic resin block in a cylindrical plastic mould. After the complete setting of resin, 
TABLE 1. Used materials and manufacturers and contents information's

\begin{tabular}{|c|c|c|c|c|}
\hline Luting Agent & Manufacturer LOT number & Type & Powder & Liquid \\
\hline Aqua Meron & $\begin{array}{l}\text { Voco, Germany } \\
1118221\end{array}$ & GIC & $\mathrm{Na}-\mathrm{Ca}$ fluorosilicate glass, Polyacrylic acid & Distilled water \\
\hline Aqua Cem & $\begin{array}{l}\text { Dentsply, USA } \\
1102002368\end{array}$ & GIC & $\begin{array}{l}\text { Na-Ca fluorophosphoroaluminiumsilicate, } \\
\text { Polyacrylic acid, Tartaric acid, Yellow Ferric }\end{array}$ & Distilled water \\
\hline Ketac Cem & $\begin{array}{l}\text { 3M ESPE, USA } \\
458814\end{array}$ & GIC & Glass powder, Polycarboxylic acid, Pigments & Water, tartaric acid, conservation agents \\
\hline Otomimix CPB & $\begin{array}{l}\text { Biomet, USA } \\
307750\end{array}$ & Bone filler & Calcium phosphate powder, sodium citrate dihydrate & anhydrous citric acid, distilled water \\
\hline
\end{tabular}

GIC: Glass ionomer cement

TABLE 2. Manipulative variations of used materials

\begin{tabular}{lcccc}
\hline Material & $\mathrm{P} / \mathrm{L}$ & Mixing Time & Working Time & Setting Time \\
\hline Aqua Meron & $3.3-3.8 / 1$ & $30 \mathrm{sec}$ & $3 \mathrm{~min}$ & $6-7 \mathrm{~min}$ \\
Aqua Cem & $3.3 / 1$ & $15 \mathrm{sec}$ & $2: 30 \mathrm{~min}$ & $3.5-5 \mathrm{~min}$ \\
Ketac Cem & $3.8 / 1$ & $1 \mathrm{~min}$ & $3: 30 \mathrm{~min}$ & $3: 4.5 \mathrm{~min}$ \\
Otomimix CPB & $1 / 1$ & $30-45 \mathrm{sec}$ & $3-4 \mathrm{~min}$ & $4-6 \mathrm{~min}$ \\
\hline
\end{tabular}

P/L: powder/liquid; sec: second; min: minute

TABLE 3. Mean SBS values and standard deviations

\begin{tabular}{lccc}
\hline Groups & N & $\begin{array}{c}\text { SBS } \\
\text { (Mean } \pm \text { Std. Error) }\end{array}$ & $\begin{array}{c}\text { Bonforonni adjusted } \\
\text { with Mann Whitney U* }\end{array}$ \\
\hline Aqua Meron & 5 & $13.28 \pm 4.13$ & A, B \\
Aqua Cem & 5 & $23.43 \pm 7.71$ & A \\
Ketac Cem & 5 & $8.51 \pm 2.31$ & B \\
Otomimix CPB & 5 & $1.78 \pm 1.21$ & C \\
\hline
\end{tabular}

*same letter indicates that there is not significantly difference at a 0.05 .

$\mathrm{N}$ : number; SBS: shear bond strength

bone surfaces were ground with a dental diamond bur instrument under water (Figure 1a). Then, after all specimens were divided into four groups randomly $(n=5)$ by using the block randomisation method (15) and cemented with three different GICs and one bone void filler. The tested materials and their compositions are summarised in Table 1. Before the cementation, all specimens were washed with water and gently dried with oil free air, but were not dehydrated, following insertion into the specific apparatus designed for SBS testing (Ultradent Production Inc., South Jordan, USA), in a manner that the cementation area ( $2 \mathrm{~mm}$ in height and diameter) was completely inside of bone border (Figure 1b, c). All materials were proportioned and handled according to the manufacturer's instructions (Table 2). After the mixing of powder and liquid, cement was carried into the hole of the apparatus with a hand instrument and moderate pressure was applied until the initial setting of cement was completed (Figure 1d).

\section{Shear bond strength testing}

The SBS of the specimens which set completely was measured after 24 hours of storage at $37^{\circ} \mathrm{C}$. The specimens were placed in a universal testing machine (Model 5565; Instron Co Ltd, Canton, Mass). Load was applied parallel to the long axis of the specimens and as close as possible to the interface between ossicles and cement, at a constant crosshead speed of $0.5 \mathrm{~mm} / \mathrm{min}$ until failure (Figure 1e). The SBS was calculated by dividing the failure load $(\mathrm{N})$ by the bonding area $\left(\mathrm{mm}^{2}\right)$ as megapascal (MPa).

\section{SEM analysis of bonding interface}

To thoroughly assess the bonding interface, a new specimen was prepared for each material. The ossicles were embedded into the auto-polymerised acrylic resin which was $2 \mathrm{~mm}$ in thickness. Then, the surface of ossicles was coated with GICs and HA bone cement. After completely setting, specimens were cut along their length using a low speed diamond saw (Isomet 1000, Buehler, Lake Bluff, IL, USA). The specimens were sputter-coated with $15 \mathrm{~nm}$ gold-palladium (Bal-Tec, SCD 050, Scotia, NY, USA) for 130 seconds at a current of 10-15 $\mathrm{mA}$ and a vacuum of $130 \mathrm{mTorr}$ and then examined by scanning electron microscope (LEO, EVO 40 XVP, Cambridge, UK) with an acceleration voltage of $20 \mathrm{KV}$ and different magnifications.

\section{Failure mode analysis and SEM evaluation}

All specimens submitted to the shear bond testing were observed using an optical light microscope (SMZ 800, Nikon, Tokyo, Japan) at 40x magnification. Failure modes were classified based on the following criteria: adhesive failure between the ossicles and the cement, cohesive failure in the resin cement, and mixed failure that included the cohesive failure of the ossicles and the cement.

To analyse the types of failure, demonstrative specimens were selected and SEM images were obtained as mentioned above.

\section{Statistical analyses}

Statistical analysis was performed using a computerized statistical software program (SPSS Statistic for Windows, Version 17.0, Chicago: SPSS Inc., USA) A Kruskal-Wallis one 
way ANOVA analysis was used to determine whether there were significant differences in SBS among the groups, followed by the Mann-Whitney U Test with Benforroni adjustment to allow comparisons between the groups. The statistical significance was set at $5 \%$.

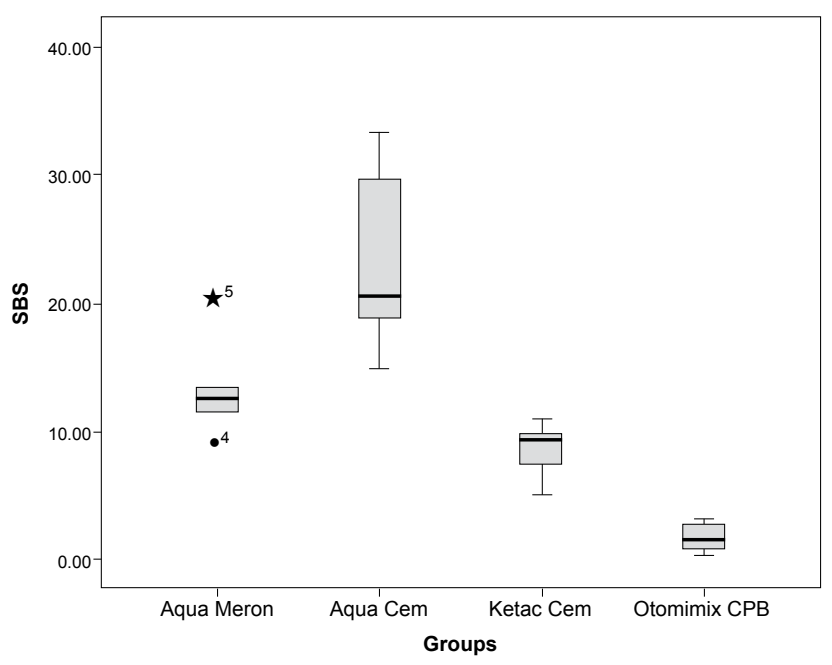

FIG. 2. SBS values of tested cements
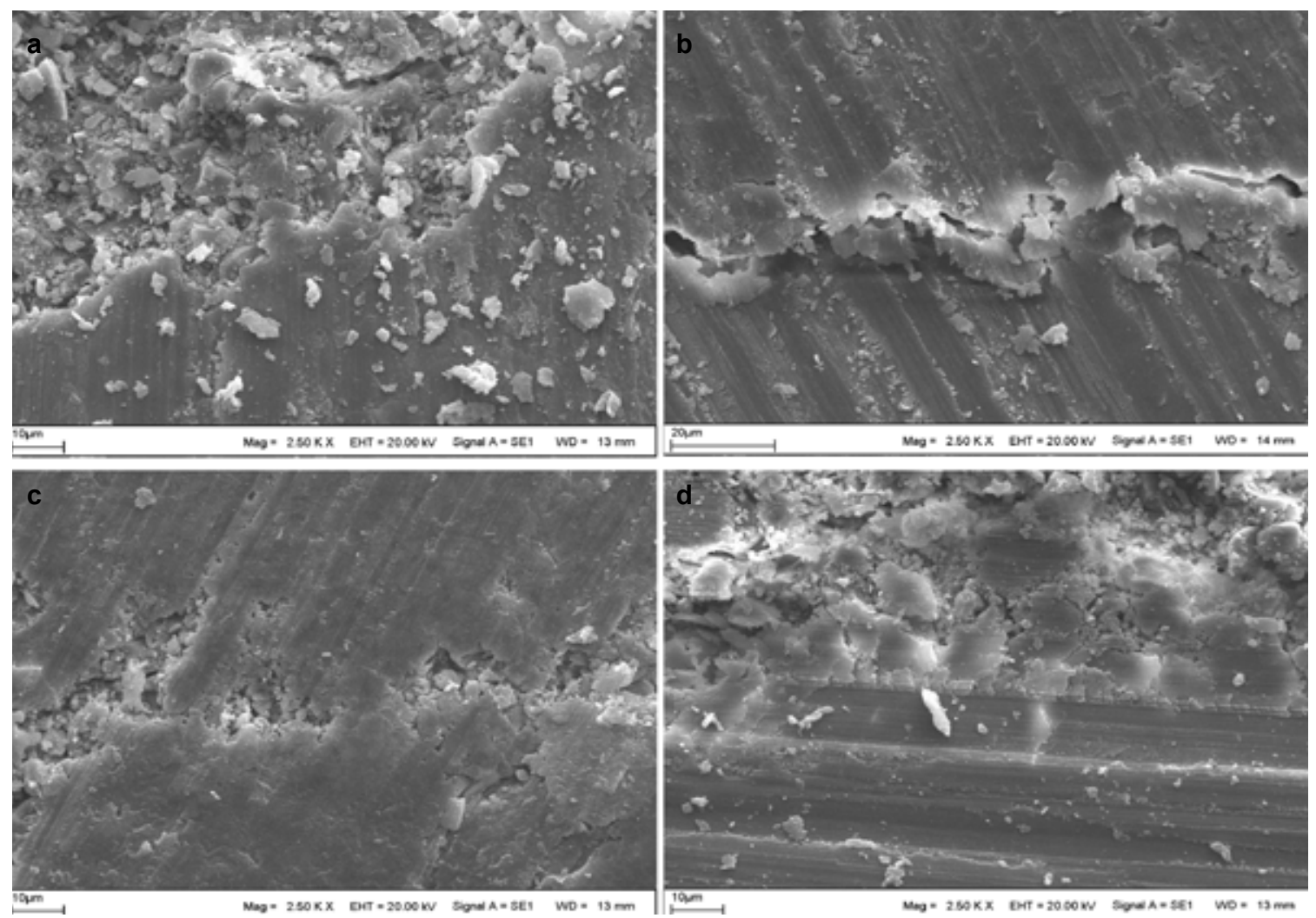

FIG. 3. a-d. SEM evaluation (x2500) of ossicle and cement interface for Aqua Meron (a), SEM evaluation (x2500) of ossicle and cement interface for Aqua Cem (b), SEM evaluation (x2500) of ossicle and cement interface for Ketac Cem (c), SEM evaluation (x2500) of ossicle and cement interface for Otomimix CPB (d) 
details. The differences between the materials used, quality of set material, and character of filler particles were better demonstrated by the application technique (Figure 3a, c). Co-polymerisation of $\mathrm{OH}$ was found to be good and without voids. However, there are significant differences of internal structures between the ossicles and $\mathrm{OH}$. In addition, $\mathrm{OH}$ presented porous and weak textures (Figure 3d).

The failure mode distribution for all specimens is presented in Figure 4. For AM, failure mode distribution was adhesive (40\%), cohesive (40\%), and mixed (20\%). For the AC and KC groups, the failure modes were mainly adhesive $(60 \%)$ and mixed (40\%). For the $\mathrm{OH}$ group, failure modes were completely adhesive $(100 \%)$. SEM images of the different failure types are presented in Figure 5a, b, c.

\section{DISCUSSION}

The natural ossicular chain conducts sound efficiently from the environment to the inner ear (1). The prosthesis aims to transmit sound to the oval window through the natural ossicular route. Although an incudostapedial clips prosthesis ensures the functional success for rehabilitation of the incus long arm defect, it increases the cost of operation (16).

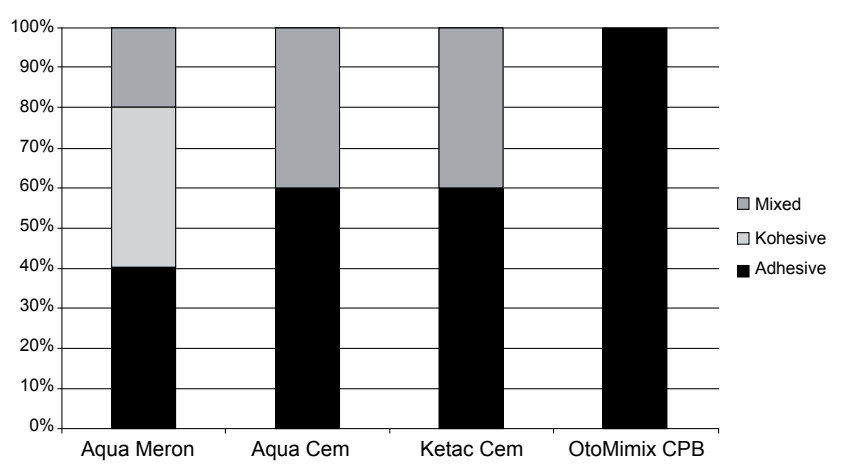

FIG. 4. Failure type analysis of tested materials
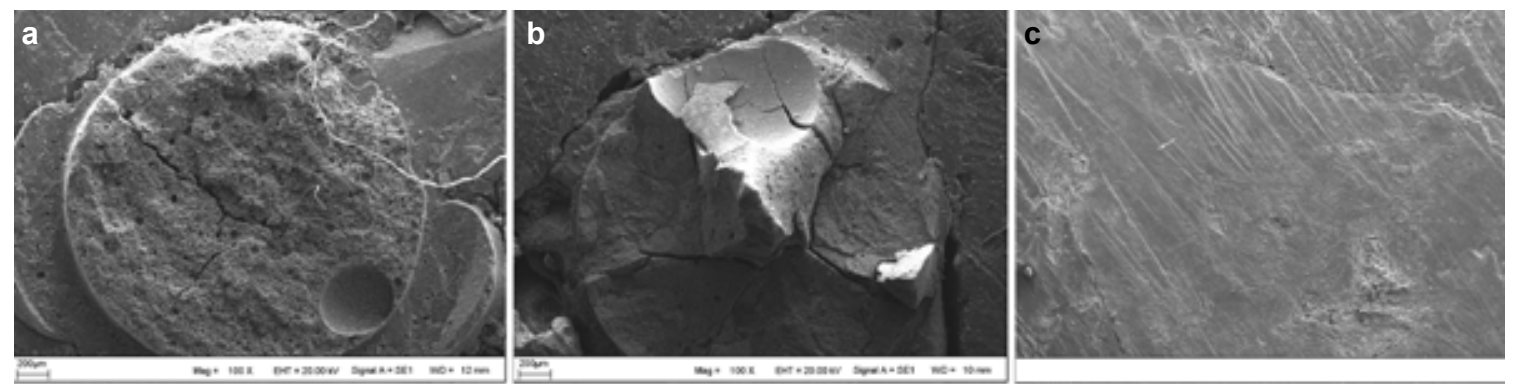

FIG. 5. a-c. Representative SEM images of different failure modes after SBS testing. SEM images (x100) of cohesive failure into the Aqua Meron GIC (a). Representative SEM images of different failure modes after SBS testing; A mixed failure of Ketac Cem GIC (x100 magnification). A part of cement crack is seen at half part of the ossicle surface (b). Representative SEM images of different failure modes after SBS testing; Adhesive failure of OtoMimix CPB specimen (x250 magnification) (c) 
study is that all GICs had higher SBS values than the HA. GICs used in this study have significantly superior SBS values (AM; $13.28 \mathrm{MPa}, \mathrm{AC} ; 23.43 \mathrm{MPa}, \mathrm{KC} ; 8.51 \mathrm{MPa})$ to the ossicular bones than the bone filler (HA, OH; $1.78 \mathrm{MPa}$ ). A variety of GICs with different contents have been used in ossiculoplasty $(4,10,11)$. It is considered that the differences among the SBS values of different GICs are due to small variations in their contents. GIC is bonded chemically to the dental hard tissue during the setting reaction. It is thought that the bonding mechanism involves the chelation of carboxyl groups of the polyacids with calcium and phosphate ions from the enamel and dentin. When the GIC is used for ossiculoplasty, an ionic interaction between the GIC and ossicles probably results in strong chemical bonds. Since GICs bond firmly to stapes, it may be difficult to remove it during a revision surgery. Thus, an inappropriate manipulation may cause stapes to fracture (19).

The use of GICs for different ossicular reconstructions such as incus stapes re-bridging, incus augmentation, and the fixation of stapes implants have been shown by several studies as the reliable method $(4,12,19,20)$. Baglam et al. reported a significant hearing improvement after incudostapedial rebridging ossiculoplasty with KC (20). Bayazit et al. presented a significant improvement in the hearing results of different aural pathologies and surgeries after two years of follow-up with bone cement ossiculoplasty (19). Righini-Grunder et al. reported their long-term experiences by using Sereno Cem and KC GICs for different kinds of ear surgeries (9). They noted some revision surgeries due to cement breakage. This study shows that the cement connection could break or debond; thus, a revision surgery may be needed.

Hydroxyapatite has been recognised as a well-tolerated material in cranioplasty and in the production of ossicular prostheses (1). In this study, $\mathrm{OH}$ showed less bonding strength to ossicles. While the GICs are mainly used as a luting material, HA is a bone filler material and could not form tight and rigid structures from the initial setting time until testing. Due to its fragile structure, there was a problem during the SBS testing for HA specimens. HA creates about $70 \%$ of bone and HA cements harden as a microporous HA. It has been shown in animal studies that HA is an osteoconductive material. Many retrospective studies also confirmed the long-term clinical success of HA. It is likely that connection at the interface between the HA and ossicles gets stronger over time due to the osteoconductive activity of HA. Goebel et al. used the Mimix, another form of $\mathrm{OH}$, to repair a variety of ossicular problems, and also reported significant improvements in functional outcomes after an 11 month follow-up (1).

Manipulative variations such as mixing time, setting time, consistency and easy application are the preferred factors for shortening the operating time for ossicular surgery. There are slight manipulative variations (Table 3) among the tested GICs and HA. Short working and setting times of GICs and HA can shorten the operation time. On the other hand, the GICs develop a putty-like consistency that makes it easy to handle and they can be applied as accurately as HA. However, ossiculoplasty with GIC is cost effective, which is an advantage (19).

Mechanical and bonding properties of GICs could be altered by the powder/liquid (P/L) ratio. In general, increasing the $\mathrm{P} / \mathrm{L}$ ratio results in higher viscosity decreasing the wetting ability of GIC on the ossicles. In contrast, the cement's properties would weaken and fluidity would increase when the ratio is lowered. Consequently, changing the $\mathrm{P} / \mathrm{L}$ ratio from the manufacturer's recommendation makes it complicated to connect the two ends of ossicles and has a negative effect on the retention and survival of the re-built part.

The hearing quality after ossiculoplasty is affected by the prostheses quality and environmental factors such as the presence or absence of malleus, dry or wet ear, or primary or revision surgery. In contrast, the GICs are moisture-sensitive materials, especially in the early setting $(10 \mathrm{~min}$.) phase. This means that a gain or loss of water from the surface in the early setting phase in clinical conditions can severely affect the final mechanical properties of the GIC. For this reason, the application area has to be dried during the operation for reliable and strong bonding and long-term clinical success. Therefore, the operator should pay a great deal of attention and effort.

The high success rate of ossiculoplasty with GICs and HA were reported by many authors. In patients requiring revision of surgery, Geyer and Helms reported that half of the failures resulted from the displacement of prosthesis (8). However, there is no information about the character of bonding failures of bone cement ossiculoplasty. If the missing part of incus is very long, the re-built part could fail adhesively or cohesively over time. To overcome this problem, establishing more reliable and stronger bonding between the remainder of the long process of the incus and the head of the stapes is preferable, instead of using a total or partial ossicular chain reconstruction prosthesis. In this study, all GICs showed firmer and more compact structures than the HA in the short-term. While $\mathrm{OH}$ showed complete adhesive failure between the ossicles, $\mathrm{HA}, \mathrm{AC}$ and $\mathrm{KC}$ were broken off mainly adhesive $(60 \%)$ and mixed (40\%). Only AM showed cohesive failure of the cement. That means that AM could prevent the ossicles from re-breaking during functioning.

According to the author's knowledge, this is the first study evaluating the bonding strength of GICs and HA to the ossicles. Nonetheless, there is still not enough knowledge in the literature about the optimum bonding criteria such as minimum bonding strength for short- and long-term success and vibration character of the prosthetic materials used during the sound transmission. Erosion of the incudostapedial joint is the most common ossicular defect encountered in chronic middle 
ear disease (20). However, behaviour of the re-built part under function has not been clarified. Several studies have reported the results of clinical performance of different GICs and bone cement by means of pre- and post-operative hearing quality for patients with various middle ear defects. However, there is no in vitro or in vivo comparative study about the bonding strength of different GICs or bone cement to the ossicles. Furthermore, there are also no stated numeric values about the bonding strength of prosthetic materials to the ossicles. Despite deep discussion on the choice of materials, Demir et al. suggested that the success rate does not depend on the type of replacement material but is extremely related to the pathophysiological status of the middle ear (3). Therefore, new comparative prospective clinical studies should be planned to verify whether the in vitro test results are compatible with the clinical conditions or not.

Ethics Committee Approval: Ethics committee approval was received for this study from the ethics committee of İnönü University.

Informed Consent: Written informed consent was obtained from patients who participated in this study.

Peer-review: Externally peer-reviewed.

Author contributions: Concept - M.T.K., İ.H.U., M.Y.; Design - M.T.K, İ.H.U.; Supervision - M.T.K.; Resource - M.T.K., İ.H.U., M.Y., M.A.M., A.T.O., F.M.H.; Materials - M.T.K.; Data Collection\&/or Processing - M.T.K., İ.H.U., A.T.O.; Analysis\&/or Interpretation - İ.H.U., M.Y., M.A.M.; Literature Search - M.T.K., İ.H.U., M.Y., M.A.M., F.M.H., A.T.O.; Writing - İ.H.U., M.A.M., F.M.H.; Critical Reviews - M.T.K., I.H.U., M.Y., M.A.M., F.M.H., A.T.O.

Conflict of Interest: No conflict of interest was declared by the authors.

Financial Disclosure: The authors declared that this study has received no financial support.

\section{REFERENCES}

1. Goebel JA, Jacob A. Use of Mimix hydroxyapatite bone cement for difficult ossicular reconstruction. Otolaryngol Head Neck Surg 2005;132:727-34. [CrossRef]

2. Kartush JM. Ossicular chain reconstruction. Capitulum to malleus. Otolaryngol Clin North Am 1994;27:689-715.

3. Bora F, Yücel Z, Ceylan S, Oltulu E, Batmaz T, Avseren E. Incudostapedial bridging ossiculoplasty with bone cement hearing results. Kulak Burun Bogaz Ihtis Derg 2010;20:169-72.

4. Kalcioglu MT, Tan M, Fleerakkers J. The use of bone cement for ossicular chain defects. Eur Arch Otorhinolaryngol 2013;270:2849-55. [CrossRef]
5. Vital V,Konstantinidis I, Vital I, Triaridis S, Constantinidis J. Cartilage-wire-fascia compact total ossicular replacement prosthesis in one-stage cholesteatoma surgery. Am J Otolaryngol 2008;29:393-7. [CrossRef]

6. Quesnel S, Teissier N, Viala P, Couloigner V, Van Den Abbeele T. Long term results of ossiculoplasties with partial and total titanium Vario Kurz prostheses in children. Int J Pediatr Otorhinolaryngol 2010;74:1226-9. [CrossRef]

7. O'Reilly RC, Cass SP, Hirsch BE, Kamerer DB, Bernat RA, Poznanovic SP. Ossiculoplasty using incus interposition: hearing results and analysis of the middle ear risk index. Otol Neurotol 2005;26:853-8. [CrossRef]

8. Geyer G, Helms J. Ionomer-based bone substitute in otologic surgery. Eur Arch Otorhinolaryngol 1993;250:253-6. [CrossRef]

9. Righini-Grunder F, Hausler R, Chongvisal S, Caversaccio M. Glass ionomer cement in otological microsurgery: experience over 16 years. Eur Arch Otorhinolaryngol 2014. DOI: 10.1007/ s00405-014-3276-z. [CrossRef]

10. Dere H, Ozdogan F, Ozcan KM, Selcuk A, Ozcan I, Gokturk G. Comparison of glass ionomer cement and incus interposition in reconstruction of incus long process defects. Eur Arch Otorhinolaryngol 2011;268:1565-8. [CrossRef]

11. Somers T, Van Rompaey V, Claes G, Salembier L, van Dinther J, Andrzei Z, et al. Ossicular reconstruction: hydroxyapatite bone cement versus incus remodelling: how to manage incudostapedial discontinuity. Eur Arch Otorhinolaryngol 2012;269:1095101. [CrossRef]

12. Ozer E, Bayazit YA, Kanlikama M, Mumbuc S, Ozen Z. Incudostapedial rebridging ossiculoplasty with bone cement. Otol Neurotol 2002;23:643-6. [CrossRef]

13. Hoffmann KK, Kuhn JJ, Strasnick B. Bone cements as adjuvant techniques for ossicular chain reconstruction. Otol Neurotol 2003;24:24-8. [CrossRef]

14. Demir UL, Karaca S, Basut O. Bone cement or incus interposition in type 2 tympanoplasty: prognostic factors and functional outcomes. Kulak Burun Bogaz Ihtis Derg 2012;22:99-104. [CrossRef]

15. Suresh KP. An overview pf randomization techniques: An unbiased assessment of outcome in clinical research. J Hum Reprod Sci 2011;4:8-11. [CrossRef]

16. Huttenbrink KB, Luers JC, Beutner D. Titanium angular clip: a new prosthesis for reconstruction of the long process of the incus. Otol Neurotol 2009;30:1186-90. [CrossRef]

17. Zoergiebel J, Ilie N. An in vitro study on the maturation of conventional glass ionomer cements and their interface to dentin. Acta Biomater 2013;9:9529-37. [CrossRef]

18. Sidhu SK. Glass-ionomer cement restorative materials: a sticky subject? Aust Dent J 2011;56 (Suppl) 1:23-30.

19. Bayazit YA, Ozer E, Kanlikama M, Durmaz T, Y1lmaz M. Bone cement ossiculoplasty: incus to stapes versus malleus to stapes cement bridge. Otol Neurotol 2005;26:364-7. [CrossRef]

20. Baglam T, Karatas E, Durucu C, Kilic A, Ozer E, Mumbuc S, et al. Incudostapedial rebridging ossiculoplasty with bone cement. Otolaryngol Head Neck Surg 2009;141:243-6. [CrossRef] 